\title{
Genetic diversity of exotic and local eggplants (Solanum spp.) cultivated in Côte d'Ivoire based on ISSR markers
}

\author{
N'GUESSAN OLIVIER KONAN ${ }^{1, \vartheta}$, MARIE ANGE AKAFFOU ${ }^{1}$, LÉONARD KOUADIO', \\ DOFFOU SÉLASTIQUE AKAFFOU ${ }^{1}$, GUY MERGEAI ${ }^{2}$ \\ ${ }^{1}$ Laboratory of Crop Improvement, Agroforestry Unit, Jean Lorougnon Guédé University. BP 236 Daloa, Côte d'Ivoire. \\ Tel.: +225-5742598, `email: nguessanolivier@yahoo.fr \\ ${ }^{2}$ Laboratory of Tropical Agroecology, Gembloux Agro-Bio Tech, Liège University. 2 passage des Déportés, B-5030 Gembloux, Belgium
}

Manuscript received: 10 June 2020. Revision accepted: 20 July 2020.

\begin{abstract}
Konan NO, Akaffou MA, Kouadio L, Akaffou DS, Mergeai G. 2020. Genetic diversity of exotic and local eggplants (Solanum spp.) cultivated in Côte d'Ivoire based on ISSR markers. Biodiversitas 21: 3651-3658. Eggplants are important vegetables in Côte d'Ivoire. Despite an increase in the cultivation of exotic genotypes and their progressive dominance over local cultivars, which could represent a threat of genetic erosion, there are not enough molecular data available on the genetic diversity of the eggplants currently cultivated in this country. This study is a contribution to the knowledge of the genetic diversity of the current eggplant cultivars grown in Côte d'Ivoire. It aimed to assess the genetic variation of nine exotic and local eggplants commonly cultivated in Côte d'Ivoire, using five inter-simple sequence repeat (ISSR) primers. The results revealed for the exotic cultivars 42 ISSR loci of which 31 were polymorphic $(73.81 \%)$, and for local cultivars 51 loci of which $49(96.08 \%)$ were polymorphic. The Nei's genetic diversity and Shannon's information index of local cultivars $(\mathrm{He}=0.3333$ and $\mathrm{I}=0.4863)$ were higher than those of exotic cultivars $(\mathrm{He}=0.2000$ and $\mathrm{I}=0.2971$ ). The Gst value and the AMOVA analysis found more than $70 \%$ of the total genetic diversity within the groups. The Jaccard's dissimilarity coefficients between the cultivars, ranged from 0.324 to 0.966 with an average of 0.741 . The clustering of genotypes with the neighbor-joining unrooted tree and PCoA analysis differentiated three main clusters with exotic cultivars grouped in cluster I and local cultivars in cluster II and III. In view of these results, the local eggplants had higher genetic diversity and constitute an interesting germplasm which needs to be conserved for potential breeding programs.
\end{abstract}

Keywords: Eggplant, genetic diversity, ISSR markers, polymorphism

\section{INTRODUCTION}

Eggplants (Solanum) represent economically important vegetables widely consumed in the world (Sultana et al. 2018). They belong to the family Solanaceae and consist of about 1500 morphologically diverse species (Aguoru et al. 2015). Three distinct cultivated species of eggplants are known: S. melongena L. (brinjal eggplant), S. macrocarpon L. (gboma eggplant), and S. aethiopicum L. (scarlet eggplant) (Wei et al. 2019). These three cultivated eggplants are autogamous diploid species $(2 \mathrm{n}=2 \mathrm{x}=24)$ and are all of Afro-Eurasian origin (Salgon et al. 2017).

S. aethiopicum and S. macrocarpon were domesticated in Africa from their wild relatives $S$. anguivi Lam. and $S$. dasyphyllum Schumach. \& Thonn., respectively (Sunseri et al. 2010). The cultivation of these two species is widespread in Africa, mainly in the west and central part, as well as in some parts of Caribbean, Brazil, and south Italy (Maundu et al. 2009; Gramazio et al. 2016). Their fruits are consumed raw or stewed with other vegetables or other protein-rich foods, whilst the glabrous leaves are boiled as green vegetables, like spinach (Sunseri et al 2010). In addition, some vegetative parts (e.g. peduncles, roots, stalks, and leaves) are used for traditional medicine (Syfert et al. 2016).

The brinjal eggplants, S. melongena, are derived from the wild African species $S$. incanum $L$. and was domesticated in India and southeast China (Taher et al. 2017). Now, brinjal eggplant is cultivated throughout the world (Ahmed et al. 2019).

Eggplants are nutritious and important sources of antioxidants, vitamins, and minerals. Their most important nutritional components are phenolic compounds that give the fruit its antioxidant properties which are beneficial for a number of metabolic and cardiovascular ailments (Syfert et al. 2016). The global production of eggplants are around 50 million tons annually, with a net value of more than US $\$ 10$ billion a year, which makes them the fifth most economically important solanaceous crop after potato, tomato, pepper, and tobacco (Taher et al. 2017).

In Côte d'Ivoire, several genotypes of eggplants with variable morphological, physiological, and qualitative characteristics are cultivated (Kouassi et al. 2014). These eggplant resources include exotic commercial cultivars belonging to $S$. melongena and local cultivars of $S$. aethiopicum, S. macrocarpon, and S. anguivi. Nowadays, there is an increase in the cultivation of exotic genotypes and their progressive dominance over local cultivars. This could represent a threat of genetic erosion, and in the longer term have negative implications by narrowing the source of useful genes present in the local germplasm and exploitable in breeding programs. Despite this threat, there are not enough studies on the genetic diversity of eggplants currently grown in this country using molecular markers. 
However, a comprehensive understanding of the molecular variation and the knowledge about the genetic relationships among these eggplant genotypes are needed for not only breeding purposes, but also for the implementation of potential genetic conservation programs (Ahmed et al. 2019).

The general objective of this study was to contribute to the molecular knowledge of the genetic diversity of current eggplant cultivars grown in Côte d'Ivoire. More specifically, the aim of the study was to analyze the genotypic variations and the genetic relationships of nine exotic and local eggplants commonly cultivated in Côte d'Ivoire using inter-simple sequence repeat (ISSR) markers.

\section{MATERIALS AND METHODS}

\section{Plant materials}

The germplasm used in this study consisted of nine eggplant genotypes commonly cultivated and marketed in Côte d'Ivoire (Table 1). It included four exotic cultivars belonging to the species $S$. melongena, four local cultivars of $S$. aethiopicum, and one local cultivar of $S$. anguivi. Five seedlings of each cultivar were grown at the experimental farm of the Laboratory of Crop improvement of Jean Lorougnon Guédé University (Daloa, Côte d'Ivoire) and leaf samples from every 2-3 weeks old seedling were collected for genomic DNA isolation. At maturity, the color, shape, and size of the fruits were observed to evaluate phenotypic differences between the cultivars.

\section{Genomic DNA isolation}

For isolation of genomic DNA, the collected fresh leaf samples were immediately dried in an oven at $65^{\circ} \mathrm{C}$ for 45 min, stored in a desiccator and ground into a fine powder with a mortar and pestle. The DNA extraction process was carried out using the Wizard $\AA$ Genomic DNA purification kit (Promega, Madison, USA) according to the manufacturer's protocol with slight modifications. Briefly, $600 \mu \mathrm{L}$ of "Nuclei Lysis Solution" was used to digest 40 $\mathrm{mg}$ of leaf powder by incubation at $65{ }^{\circ} \mathrm{C}$ for 15 minutes. The proteins were then precipitated with $200 \mu \mathrm{L}$ of "Protein Precipitation Solution", using a vigorous vortex at high speed for 20 seconds and centrifugation for 3 minutes at $15,000 \times \mathrm{g}$. The supernatant containing the DNA was gently mixed with $600 \mu \mathrm{L}$ of isopropanol at room temperature and the DNA was pelleted by centrifugation at $15,000 \times \mathrm{g}$ for 1 minute. The DNA pellet was washed with $70 \%$ ethanol and air-dried. The air-dried DNA was dissolved in $100 \mu \mathrm{L}$ of "DNA Rehydration Solution" overnight. The final DNA solution was treated with $2 \mu \mathrm{L}$ of "RNAse solution" by incubation at $37{ }^{\circ} \mathrm{C}$ for 30 minutes. The quality and quantity of the DNA were checked by electrophoresis on $1 \%$ agarose gel and the Genomic DNA of the five plants of each genotype were bulked and diluted to $50 \mathrm{ng} / \mu \mathrm{L}$ of working solution. The samples were stored at $-20^{\circ} \mathrm{C}$ until use.

\section{Polymerase chain reaction (PCR)}

For polymerase chain reaction, five ISSR primers (Table 2) selected from previous studies (Mansour et al. 2010; Ali et al. 2011; Al-Turki and Basahi, 2015; Khalifa et al. 2016) on the basis of their high discriminating capacity were used. These primers were synthesized by Integrated DNA Technologies (Coralville, Iowa, USA). PCR amplifications were performed in a final volume of 15 $\mu \mathrm{L}$, containing $50 \mathrm{ng}$ DNA, $0.3 \mu \mathrm{M}$ of ISSR primer, 200 $\mu \mathrm{M}$ of dNTPs, 1X Green Go Taq Flexi Buffer (Promega, USA), 1.25 unit of Go Taq G2Flexi DNA Polymerase (Promega, USA), and sterile $\mathrm{ddH} 2 \mathrm{O}$. PCR reaction was carried out in a Prime thermal cycler (Techne $\left.{ }^{\circledR}, \mathrm{UK}\right)$. The DNA amplification program consisted of an initial denaturation at $94^{\circ} \mathrm{C}$ for $2 \mathrm{~min}$, followed by 35 cycles of denaturation at $94^{\circ} \mathrm{C}$ for $30 \mathrm{~s}$, annealing at primer specific annealing temperature for $45 \mathrm{~s}$, and extension at $72^{\circ} \mathrm{C}$ for 2 min. After the last cycle, a final step of $5 \mathrm{~min}$ at $72{ }^{\circ} \mathrm{C}$ was included to allow complete extension of all amplified fragments, and the samples were held at $4{ }^{\circ} \mathrm{C}$.

\section{Visualization of PCR products}

The final amplified products were subjected to $45 \mathrm{~min}$ electrophoresis at $100 \mathrm{~V}$ on $2 \%$ agarose gel containing 1 $\mu \mathrm{L}$ ethidium bromide $(10 \mathrm{mg} / \mathrm{L})$ in $0.5 \mathrm{X}$ tris-boric acidEDTA buffer. After electrophoresis, the DNA profiles were visualized on a UV transilluminator in a gel documentation system and photographed for analysis.

Table 1. List of eggplant cultivars studied

\begin{tabular}{lll}
\hline \multicolumn{1}{c}{ Cultivar name } & \multicolumn{1}{c}{ Species } & \multicolumn{1}{c}{ Origin } \\
\hline Tiger & S. melongena & Exotic eggplant \\
Italy & S. melongena & Exotic eggplant \\
Kalenda & S. melongena & Exotic eggplant \\
Melina & S. melongena & Exotic eggplant \\
Meketan & S. aethiopicum & Local eggplant \\
Niguema & S. aethiopicum & Local eggplant \\
Bello & S. aethiopicum & Local eggplant \\
Kotobi (or N'Drowa) & S. aethiopicum & Local eggplant \\
Gnangnan & S. anguivi & Local eggplant \\
\hline
\end{tabular}

Table 2. List of ISSR primers used with their base sequence, repeat motif, GC content, and annealing temperature (Tm)

\begin{tabular}{lllcc}
\hline \multicolumn{1}{c}{ Primer name } & \multicolumn{1}{c}{ Sequence (5'-3') } & Repeat Motif & GC content $(\%)$ & Annealing temp. $\left({ }^{\circ} \mathbf{C}\right)$ \\
\hline ISSR 1 & CACTCCTCCTCCTCCTCC & CAC (TCC)5 & 66.7 & 56.2 \\
ISSR 9 & CTCCTCCTCCTCCTCCTC & (CTC)6 & 66.7 & 55.7 \\
ISSR 17899A & CACACACACACAAG & (CA)6 AG & 50 & 43.3 \\
ISSR 17899B & CACACACACACAG & (CA)6 G & 53.8 & 42.0 \\
ISSR DAT & GAGAGAGAGAGAGAAC & (GA)7 AC & 50 & 44.0 \\
\hline
\end{tabular}




\section{ISSR band scoring and data analysis}

Each ISSR resolved band on the gel was scored as present (1) or absent (0) and data was entered in a binary data matrix as discrete variables. The numbers of monomorphic and polymorphic amplification products for each primer were determined and the levels of polymorphism were calculated by dividing the polymorphic bands from the total scored bands. POPGENE software (version 1.32) was used to calculate observed number of alleles $(\mathrm{Na})$, effective number of alleles $(\mathrm{Ne})$, Nei's genetic diversity $(\mathrm{He})$, and Shannon's information index (I). Mean coefficient of gene differentiation (Gst) was also calculated by POPGENE software. Dissimilarity coefficients between the genotypes, in a pairwise comparison, were computed using Jaccard's coefficients of dissimilarity to estimate relationships between the genotypes studied. The resulting dissimilarity matrix was subjected to cluster analysis by Neighbor-Joining method and an unrooted tree, showing the distance-based interrelationship among the genotypes, was generated using FreeTree software (Pavlicek et al. 1999) and the drawing program (http://taxonomy.zoology.gla.ac.uk/rod/treeview.html).

Analysis of molecular variance (AMOVA) was carried out with GenALEx 6.5 software (Peakall and Smouse, 2001) to examine total genetic variation among and within groups. In addition, Principal Component Analysis (PCoA) was performed with the same software, in order to more effectively view the patterns of genetic distance. GenALEx software was also used to calculate Nei's unbiased genetic distance among the different groups of genotypes. Nei's unbiased genetic distance is an accurate estimate of the number of gene differences per locus when populations are small (Nei, 1978).

\section{RESULTS AND DISCUSSION}

\section{Morphology of the fruits of the eggplant cultivars studied}

The observation at maturity of the fruits of the eggplants studied clearly showed distinctions between them. The size, shape, and color of the fruits were characteristic for each cultivar (Figure 1). The exotic cultivars had the longest and largest fruits (Kalanda first, then Tiger, Melina, and Italy). Except for Italy which had white fruits, all three other exotic cultivars had purple fruits (dark purple for Kalanda and Melina and light purple striped for Tiger). The local cultivars showed variable fruit sizes but globally smaller than exotic eggplants; in particular, the cultivar Gnangnan presented very small fruits. The shape and color of the fruits were also variable and characteristic for each local cultivar.

\section{Profiling of ISSR bands and molecular levels of polymorphism}

The number of amplified ISSR loci and the percentage of polymorphism produced by each of the five primers used are presented in Table 3. An example of ISSR gel is illustrated in Figure 2.

Considering only exotic eggplants, 42 ISSR loci were revealed, of which $31(73.81 \%)$ were polymorphic. The percentage of polymorphism from each primer ranged from 57.14 (ISSR DAT) to $100 \%$ (ISSR 09). With regard to local cultivars, 51 ISSR loci were scored, of which 49 $(96.08 \%)$ were polymorphic. The percentage of polymorphism from each primer varied from 93.75 (ISSR 17899A) to $100 \%$ (ISSR 1, ISSR 9, and ISSR 17899B). For all the eggplant cultivars (Exotic + Local), the five ISSR primers revealed 60 loci with an average of 12 loci per primer. The highest number of loci (17) was generated by primer ISSR 17899A and the lowest (7) by primer ISSR 17899B. All the 60 amplified loci were polymorphic across the studied eggplants, accounting for $100 \%$ of polymorphism.

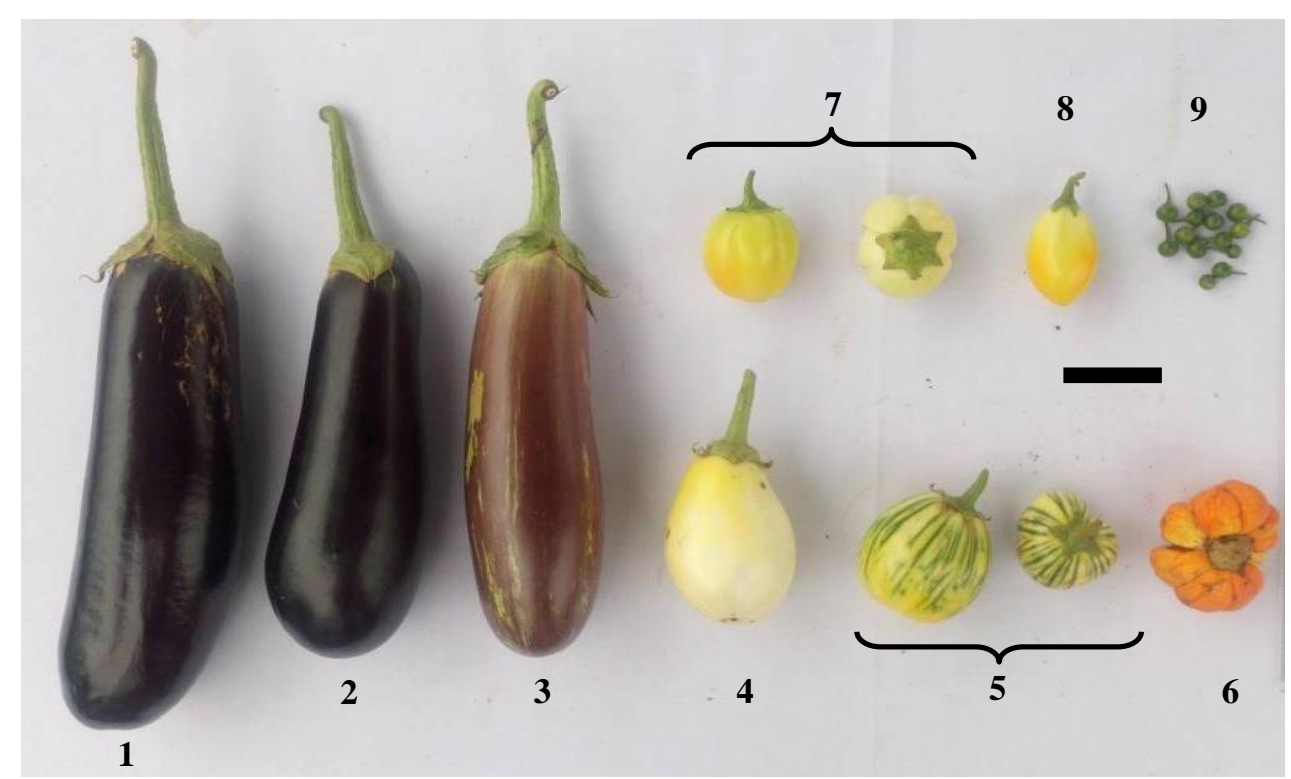

Figure 1. Fruit morphologies of the nine eggplant cultivars studied: 1. Kalenda, 2. Melina, 3. Tiger, 4. Italy, 5. Bello, 6. Meketan, 7. Kotobi (or N'Drowa), 8. Niguema, 9. Gnangnan. Bar $=5 \mathrm{~cm}$ 


\section{Genetic diversity revealed with descriptive statistics}

The values of the diversity parameters obtained from the analysis of the eggplants using the POPGENE software are presented in Table 3 . The local eggplant cultivars had the highest values for observed number of alleles $(\mathrm{Na})$, effective number of alleles (Ne), Nei's genetic diversity (He), and Shannon's information index (I) with 1.8167, $1.5879,0.3333$ and 0.4863 respectively. The exotic cultivars showed the lowest relative values for these parameters $(\mathrm{Na}=1.5167, \mathrm{Ne}=1.3300, \mathrm{He}=0.2000$ and $\mathrm{I}$ $=0.2971)$. The values of the parameters of genetic diversity for the overall eggplants studied (Exotic + Local) were $\mathrm{Na}$ $=2.0000, \mathrm{Ne}=1.6301, \mathrm{He}=0.3679$ and $\mathrm{I}=0.5479$.

The analysis of molecular variance (AMOVA) showed $14 \%$ of molecular variance among groups, while within the groups this value was $86 \%$ (Figure 3 ). The value of the coefficient of gene differentiation (Gst) was 0.2627 and Nei's unbiased measure of genetic distance (GD) between the two groups of eggplants was 0.2490 .

\section{Genetic relationships among the studied eggplants}

Genetic relationships among the eggplant cultivars were determined by neighbor-joining analysis with Jaccard's coefficients. The analysis was based on the number of loci that were different between any given pair of cultivars and a dissimilarity matrix was developed (Table 4). Basically, the value of the Jaccard's coefficients between two genotypes is an indication of their genetic similarity or dissimilarity. A pair of genotypes with a higher value is more different than a pair with a lower value.

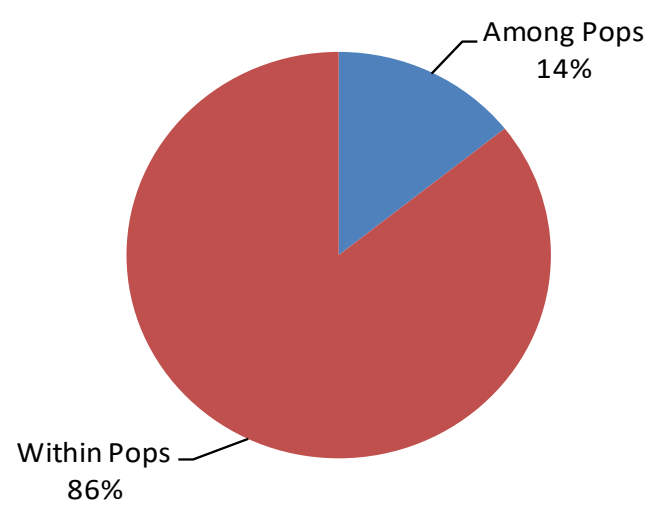

Figure 3. Result of the Analysis of Molecular Variance (AMOVA) performed with GenALEx 6.5 software in the nine eggplant cultivars.
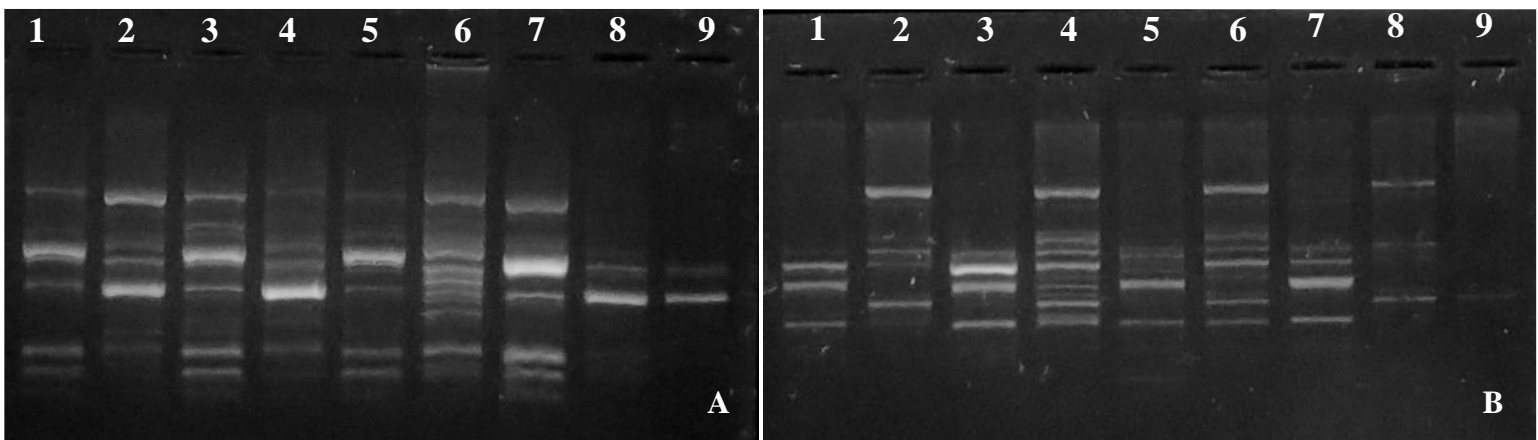

Figure 2. ISSR marker profiles of the nine eggplant cultivars studied with A. ISSR 17899A and B. ISSR DAT: 1. Tiger, 3. Gnangnan, 4. Italy, 5. Niguema, 6. Kalenda, 7. Kotobi, 8. Meketan, 9. Bello

Table 3. Levels of polymorphism detected with the five ISSR primers used in the eggplant cultivars studied and values of diversity parameters assessed by POPGENE software

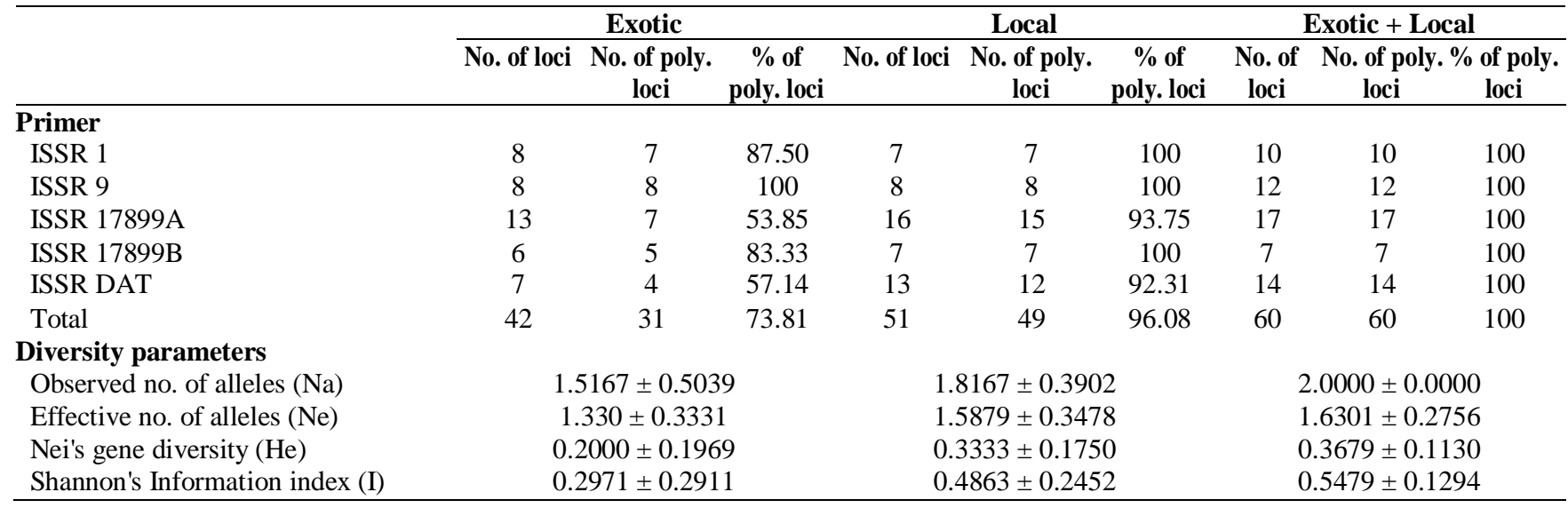


Table 4. Dissimilarity matrix presenting Jaccard's dissimilarity coefficients between the nine eggplant cultivars based on ISSR data

\begin{tabular}{|c|c|c|c|c|c|c|c|c|c|}
\hline & Tiger & Italy & Kalenda & Melina & Meketan & Gnangnan & Niguema & Kotobi & Bello \\
\hline Tiger & 0 & & & & & & & & \\
\hline Italy & 0.552 & 0 & & & & & & & \\
\hline Kalenda & 0.538 & 0.500 & 0 & & & & & & \\
\hline Melina & 0.500 & 0.606 & 0.600 & 0 & & & & & \\
\hline Meketan & 0.758 & 0.853 & 0.833 & 0.676 & 0 & & & & \\
\hline Gnangnan & 0.765 & 0.788 & 0.800 & 0.789 & 0.742 & 0 & & & \\
\hline Niguema & 0.667 & 0.750 & 0.789 & 0.783 & 0.775 & 0.529 & 0 & & \\
\hline Kotobi & 0.683 & 0.632 & 0.737 & 0.739 & 0.786 & 0.595 & 0.324 & 0 & \\
\hline Bello & 0.933 & 0.966 & 0.917 & 0.839 & 0.550 & 0.929 & 0.947 & 0.950 & 0 \\
\hline
\end{tabular}

With regard to the group of exotic cultivars, the dissimilarity coefficients between them varied from 0.500 (Italy vs Kalanda and Tiger vs Melina) to 0.606 (Italy vs Melina) with an average of 0.549 . For the group of local cultivars, the dissimilarity coefficients ranged from 0.324 (Niguema $v s$ Kotobi) to 0.950 (Kotobi vs Bello) with an average of 0.7127 . The Jaccard's coefficients for the overall cultivars studied ranged from 0.324 (lowest genomic dissimilarity) to 0.966 (full genomic dissimilarity) with a mean of 0.741 . The closest relationship was scored between the two local cultivars Niguema and Kotobi (dissimilarity of 0.324 ) and the most distant relationship was found between the exotic cultivar Italy and the local cultivar Bello (dissimilarity of 0.966 ).

\section{Dendrogram and PCoA clustering analyses}

An unrooted tree based on the neighbor-joining method (Figure 4) was constructed from the Jaccard's dissimilarity matrix to show the genetic relatedness between the genotypes. The unrooted tree divided the analyzed eggplant cultivars into three clusters (I, II, III). Cluster I included all the exotic cultivars (Tiger, Italy, Kalenda, and Melina), while the local cultivars were divided into Cluster II (Niguema, Kotobi, and Gnangan) and Cluster III (Meketan and Bello).

To visualize in detail the genetic relatedness between the eggplant cultivars, a principal coordinates analysis (PCoA) was performed for the 60 loci generated by the ISSR primers. The first and second principal coordinates account for $56.15 \%$ (32.15\% and $24 \%$ respectively) of the total variation. The result of the PCoA analysis is presented in Figure 5. It revealed a large dispersion of the cultivars on the PCoA plot, reflecting a wide genetic base. It shows a clear separation of the nine cultivars into three groups, each group is distinct from the other groups. The PCoA clearly separated the local cultivars from the exotic cultivars and divided the local cultivars into two clusters, consistent with the unrooted tree generated by the neighbor-joining method.

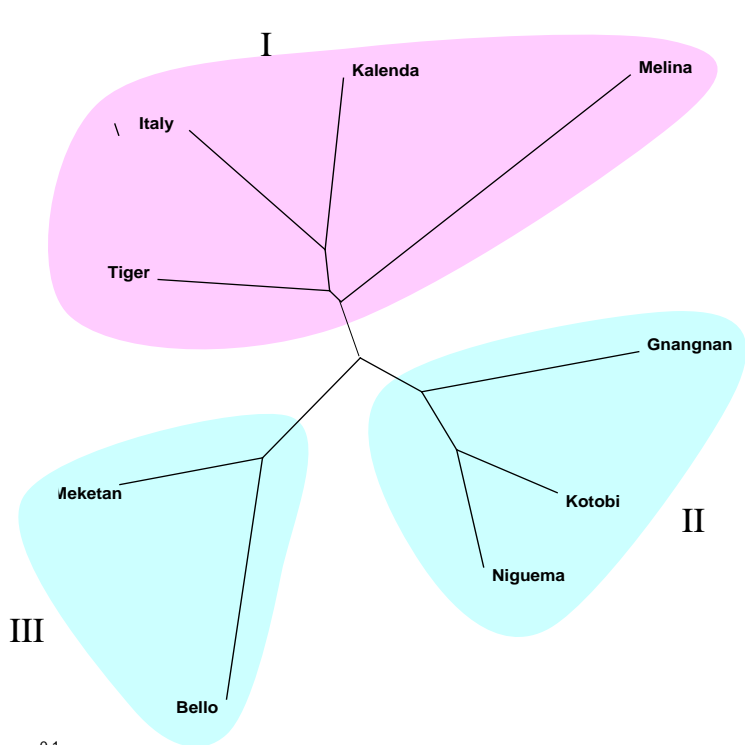

Figure 4. Unrooted tree showing the variability and relationship among the eggplant cultivars, based on the neighbor-joining method and the dissimilarity coefficients of Jaccard derived from ISSR data.

\section{Principal Coordinates (PCoA)}

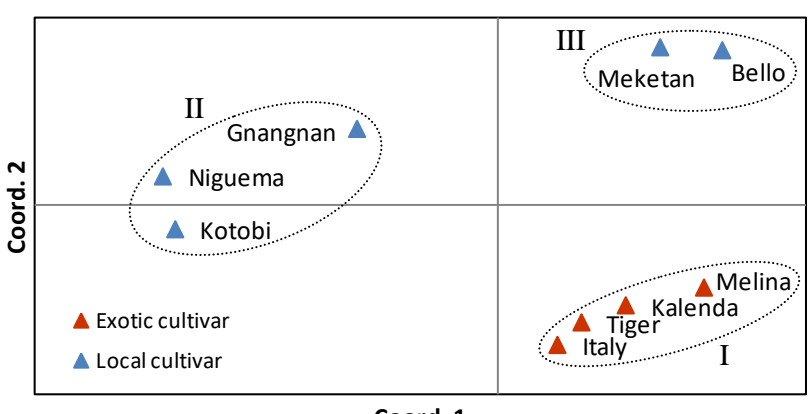

Coord. 1

Figure 5. Relationships between the nine eggplant cultivars according to the principal coordinate analysis (PCoA) based on the ISSR data. The first and second coordinates account $32.15 \%$ and $24 \%$ of the total variation, respectively.

\section{Discussion}

In the present study, nine exotic and local eggplants commonly cultivated and marketed in Côte d'Ivoire were examined for diversity analysis using ISSR markers. 
Assessment of genetic diversity within germplasm is of interest for practical applications such as the conservation of genetic resources and for breeding purposes (Gramazio et al. 2019). Information on diversity can be generated through DNA fingerprinting approaches capable to reveal large number of loci and polymorphisms among genotypes (Mangal et al. 2016). The five ISSR primers used in the present study gave successful amplification and generated a high number of loci (60). This molecular analysis revealed high polymorphism levels among the eggplants, indicating the effectiveness of this marker technology to give adequate distinctions among the genotypes studied. Mahmoud and El-Mansy (2012) studying ten cultivars of eggplant with four ISSR primers also found high levels of polymorphism ranging from $70.00 \%$ to $100 \%$. Likewise, Isshiki et al. (2008) using ISSR markers on eight Japanese eggplants and 12 related Solanum species reported a high percentage of polymorphism (99.1\%). According to Mahmoud and El-Mansy (2012), the effectiveness of this dominant microsatellite-based molecular marker is due to its ability to access variation in the numerous microsatellite regions dispersed across the genomes. Actually, this class of molecular markers is based on inter-tandem repeats of short DNA sequences (Shrivastava et al. 2018). These regions lie within the microsatellite repeats and offer great potential to determine intra-genomic and inter genomic differences (Shrivastava et al. 2018; Husnudin et al. 2019).

The high levels of polymorphism found among the eggplants studied are consistent with the important morphological differences presented by their fruits in terms of shape, size, and color. Morphological variations of fruits are among the most notable distinguishing features of eggplants and they are the result of genes involved in adaptive evolution (Tümbilen et al. 2011; Cakir et al. 2017; Gramazio et al. 2019).

The analysis showed that local eggplants had the highest number of loci and the highest percentage of polymorphic loci. Similarly, the values of Nei's genetic diversity (He) and Shannon's information index (I) of these cultivars were higher than those of exotic ones. These results indicate a greater genetic diversity of local eggplants. The relatively lower genetic variability of exotic cultivars could be due to a narrower genetic background, resulting probably from more intensive breeding efforts on S. melongena (Ge et al. 2013; Augustinos et al. 2016).

The total genetic variation of the germplasm studied, revealed by the parameters of genetic diversity, was somewhat high $(\mathrm{He}=0.3697$ and $\mathrm{I}=0.5479)$. This is confirmed by the large range of Jaccard's dissimilarity coefficients $(0.324$ to 0.966 with a mean of 0.741$)$ and the wide dispersion of the cultivars on the PCoA plot. The analysis of molecular variance (AMOVA) partitioned this total genetic variance into variance among groups (14\%) and within groups $(86 \%)$. The same trend was obtained with the coefficient of gene differentiation (Gst). Gst value was 0.2627 , suggesting that $73.73 \%$ of the total genetic diversity resided within groups and only $26.27 \%$ occurred among groups. All these results indicate that most of the total genetic variation resided within the groups; and as shown by the analysis of polymorphism and the values of the diversity parameters the greatest divergence within groups was found in local cultivars. This larger diversity of local genotypes is interesting and suggests the possibility of this material to host more different genes, which may be useful for breeding (Augustinos et al. 2016). The cultivars that showed most molecular dissimilarity are expected to contain the greatest number of different genes (Souframanien and Gopalakrishna, 2004). The cultivar Bello exhibited the highest dissimilarity coefficients $v s$ the other cultivars with values superior to 0.800 except with Meketan (0.550). This indicates the singular genetic background of Bello, which therefore appears to be an interesting cultivar for breeding.

Both the unrooted tree and the PCoA analysis clearly separated local cultivars from exotic cultivars. This highlights the limited genetic exchanges experienced by the two types of eggplants. This result confirms the genetic difference between African and Bringal eggplants as also reported by Ansari et al. (2014) using SSR markers.

Exotic eggplants showed closer aggregation on the PCoA plot compared to local cultivars, indicating their closest relationship and therefore confirming their moderate genetic diversity. It is assumed that $S$. melongena genotypes have been subjected to intense domestication and selection, and have seen their gene pool decreased compared to the local African genotypes (Wei et al. 2019). Hence, local African genotypes are generally recognized as being more diverse and having interesting genes such as genes for resistance to pathogens, diseases, or extreme environmental stresses. For example, S. aethiopicum is believed to be a potential source of abiotic and biotic resistance for cultivars of $S$. melongena (Wei et al. 2019). This suggests the possibility that some local and exotic genotypes could be used as promising parents for hybridization in order to obtain a high heterotic response and thus contribute to eggplant breeding.

The local cultivars were divided into two clusters (cluster II and cluster III). This indicates the existence of two different genetic groups in this germplasm. These two groups could be assimilated to one or the other of the groups of $S$. aethiopicum. Indeed, this species is recognized to have four groups: i) the Gilo group which include plants with edible fruits and inedible leaves; ii) the Kumba group, which comprised plants with edible leaves and fruits; iii) the Shum group which include plants with edible leaves, but the fruits are inedible; iv) and the Aculeatum group, which are ornamental plants (Plazas et al. 2014; Taher et al. 2017). In accordance with these descriptions, Cluster II which includes genotypes with edible fruits and inedible leaves could be assimilated to the Gilo group and Cluster III which includes genotypes with edible fruits and leaves could be assimilated to the Kumba group. Thus, the ISSR markers successfully helped to discriminate these two groups of $S$. aethiopicum among the local genotypes studied. However, the presence of Gnangnan in Cluster II (Gilo group) is surprising. Actually, this genotype belongs to the species $S$. anguivi (Hanelt et al. 2001) and therefore it was expected to plot alone, separately from $S$. aethiopicum genotypes. Its presence in the $S$. aethiopicum Gilo group in the present study indicates a possible close 
relationship between them. This is consistent with the finding of Adeniji et al. (2012) who, using SSR markers, found a genetic similarity between the Gilo group of $S$. aethiopicum and $S$. anguivi. The fact that $S$. aethiopicum was domesticated in Africa from $S$. anguivi (Lester and Niakan, 1986; Taher et al. 2017) could partly explain the genetic relationships observed. Moreover, the crops association usually practiced by local farmers in the villages, where Gnangnan is often cultivated with other eggplants of the Gilo group (the most cultivated local eggplants) could have favored gene exchanges, resulting in the close genetic relationships found. Indeed, $S$. aethiopicum and $S$. anguivi are interfertile and hybrids between them are fully fertile (Plazas et al. 2016; Taher et al. 2017).

In conclusion, this study has successfully used ISSR markers to determine the level of genetic diversity of the eggplant cultivars investigated. Our results highlighted a higher genetic diversity of local eggplants compared to that of the exotic ones. This makes the local cultivars a promising material that can be of interest not only for conservation purposes but also for breeding programs. Another important finding that should be considered is the clear genetic distinction between local and exotic cultivars, as revealed by the unrooted tree and the principal component analysis. This information suggests the possibility to obtain a high heterotic response through hybridization between local and exotic genotypes. Our results also showed a clear differentiation of local genotypes into two groups which can be assimilated to the Gilo and Kumba group of S. aethiopicum. Overall, these findings improved our knowledge about the situation of the genetic diversity of eggplants cultivated in Côte d'Ivoire and gave useful information for the successful management of this germplasm for breeding programs.

\section{REFERENCES}

Adeniji OT, Kusolwa P, Reuben SOWM, Deo P. 2012. Molecular diversity among seven Solanum (eggplant and relatives) species assessed by simple sequence repeats (SSRs) markers. Afr J Biotechnol 11 (90): 15643-15653.

Aguoru CU, Omoigui LO, Olasan JO. 2015. Population genetic study of eggplants (Solanum) species in Nigeria, Tropical West Africa, using molecular markers. Int $\mathrm{J}$ Plant Res 5 (1): 7-12. DOI: 10.5923/j.plant.20150501.02

Ahmed F, Rabbani MG, Islam MR, Rahman M, Malek MA, Islam MM, Emon RM. 2019. Molecular characterization of some brinjal genotypes (Solanum melongena L) using simple sequence repeat (SSR) markers. Afr J Agric Res 14 (35): 1980-1989. DOI: 10.5897/AJAR2019.14449

Ali Z, Xu ZL, Zhang DY, He XL, Bahadur S, Yi JX. 2011. Molecular diversity analysis of eggplant (Solanum melongena) genetic resources. Genet Mol Res 10: 1141-1155.

Al-Turki TA, Basahi MA. 2015. Assessment of ISSR based molecular genetic diversity of Hassawi rice in Saudi Arabia. Saudi J Biol Sci 22: 591-599.

Augustinos AA, Petropoulos C, Karasoulou V, Bletsos F, Papasotiropoulos V. 2016. Assessing diversity among traditional Greek and foreign eggplant cultivars using molecular markers and morphometrical descriptors. Span J Agric Res 14 (4): e0710. DOI: 10.5424/sjar/2016144-9020

Cakir Z, Balkaya A, Saribas S, Kandemir D. 2017. The morphological diversity and fruit characterization of Turkish Eggplant (Solanum melongena L.) populations. Ekin J Crop Breed Genetic 3 (2): 34-44.
Ge H, Liu Y, Jiang M, Zhang J, Han H, Chen H. 2013. Analysis of genetic diversity and structure of eggplant populations (Solanum melongena L.) in China using simple sequence repeat markers. Sci Hort 162: 71 75. DOI: $10.1016 /$ j.scienta.2013.08.004

Gramazio P, Blanca J, Ziarsolo P, Herraiz FJ, Plazas M, Prohens J, Vilanova S. 2016. Transcriptome analysis and molecular marker discovery in Solanum incanum and $S$. aethiopicum, two close relatives of the common eggplant (Solanum melongena) with interest for breeding. BMC Genom 17: 300. DOI: 10.1186/s12864-016-26314

Gramazio P, Chatziefstratiou E, Petropoulos C, Chioti V, Mylona P, Kapotis G, Vilanova S, Prohens J, Papasotiropoulos V. 2019. Multilevel characterization of eggplant accessions from Greek Islands and the mainland contributes to the enhancement and conservation of this germplasm and reveals a large diversity and signatures of differentiation between both origins. Agronomy 9: 887. DOI: 10.3390/agronomy912088

Hanelt P, Büttner R, Mansfeld R. 2001. Mansfeld's encyclopedia of agricultural and horticultural crops: except ornamentals. Springer Berlin, Heidelberg.

Husnudin UB, Daryono BS, Purnomo. 2019. Genetic variability of Indonesian Eggplant (Solanum melongena) based on ISSR markers. Biodiversitas 20 (10): 3049-3055. DOI: 10.13057/biodiv/d201038

Isshiki S, Iwata N, Khan MMR. 2008. ISSR variations in eggplant (Solanum melongena L.) and related Solanum species. Sci Hortic 117: 186-190. DOI: 10.1016/j.scienta.2008.04.003

Khalifa NS, Shehata MM, Abodoma AF, Alkumbezy AF. 2016. Molecular analysis of commercial date palm cultivars in Lybia using ISSR and SRAP PCR-based markers. Genetika 48 (1): 307-322. DOI: 10.2298/GENSR1601307K

Kouassi A, Béli-Sika E, Tian-Bi T, Alla-N'Nan O, Kouassi AB, N'Zi JC, N'Guetta AS, Tio-Tour B. 2014. Identification of three distinct eggplant subgroups within the Solanum aethiopicum Gilo group from Côte d'Ivoire by morpho-agronomic characterization. Agriculture 4 (4): 260-273. DOI: 10.3390 /agriculture 4040260

Lester RN, Niakan L. 1986. Origin and domestication of the scarlet eggplant, Solanum aethiopicum L., from S. anguivi Lam. In: D'Arcy WG (eds) Solanaceae: Biology and systematics. Columbia University Press, New York.

Mahmoud MI, El-Mansy AB. 2012. Molecular identification of eggplant cultivars (Solanum melongena L.) using ISSR markers. J Appl Sci Res 8 (1): 69-77.

Mangal M, Upadhyay P, Kalia P. 2016. Characterization of cultivated and wild genotypes of brinjal (Solanum melongena L.) and confirmation of hybridity using microsatellite markers. Vegetos 29: 2. DOI: 10.5958/2229-4473.2016.00016.1

Maundu P, Achigan-Dako E, Morimoto Y. 2009. Biodiversity of African vegetables. In: Shackleton CM, Pasquini MW, Drescher AW (eds) African indigenous vegetables in urban agriculture. MapSet Ltd, UK.

Nei M. 1978. Estimation of average heterozygosity and genetic distance from a small number of individuals. Genetics 89: 583-590.

Pavlicek A, Hrda S, Flegr J. 1999. FreeTree - freeware program for construction of phylogenetic trees on the basis of distance data and bootstrap/jackknife analysis of the tree robustness. Application in the RAPD analysis of genus Frenkelia. Folia Biol 45:97-99.

Peakall R, Smouse PE. 2001. GenAlExV5: Genetic Analysis in Excel. Population genetic software for teaching and research. Australian National University, Canberra, Australia. (Online) Available with updates at http://www.anu.edu.au/BoZo/GenAlEx/

Plazas M, Andújar I, Vilanova S, Gramazio P, Herraiz FJ, Prohens J. 2014. Conventional and phenomics characterization provides insight into the diversity and relationships of hypervariable scarlet (Solanum aethiopicum L.) and gboma (S. macrocarpon L.) eggplant complexes. Front Plant Sci 5: 318. DOI: 10.3389/fpls.2014.00318

Plazas M, Vilanova S, Gramazio P, Rodríguez-Burruezo A, Fita A, Herraiz FJ. 2016. Interspecific hybridization between eggplant and wild relatives from different gene pools. J Am Soc Hort Sci 141: 3444.

Salgon S, Jourda C, Sauvage C, Daunay M-C, Reynaud B, Wicker E, Dintinger J. 2017. Eggplant resistance to the Ralstonia solanacearum species complex involves both broad-spectrum and strain-specific quantitative trait loci. Front Plant Sci 8: 828. DOI: 10.3389/fpls.2017.00828

Shrivastava S, Sharma S, Das P. 2018. Screening and identification of molecular marker for fingerprinting of brinjal hybrids and its parental lines. Int J Curr Biotechnol 6 (1):1-5. 
Souframanien J, Gopalakrishna T. 2004. A comparative analysis of genetic diversity in blackgram genotypes using RAPD and ISSR markers. Theor Appl Genet 109: 1687-1693. DOI: 10.1007/s00122004-1797-3

Sultana S, Islam MN, Hoque ME. 2018. DNA fingerprinting and molecular diversity analysis for the improvement of brinjal (Solanum melongena L.) cultivars. J Adv Biotechnol Exp Ther 1 (1): 01-06. DOI: $10.5455 /$ jabet.d1

Sunseri F, Polignano GB, Alba V, Lotti C, Bisignano V, Mennella G, Alessandro AD, Bacchi M, Riccardi P, Fiore MC, Ricciardi L. 2010. Genetic diversity and characterization of African eggplant germplasm collection. Afr J Plant Sci 4 (7): 231-41

Syfert M, Castañeda-Álvarez NP, Khoury C, Särkinen T, Sosa CC Achicanoy HA, Bernau V, Prohens J, Daunay MC, Knapp S. 2016. Crop wild relatives of the brinjal eggplant (Solanum melongena) poorly represented in genebanks and many species at risk of extinction. Am J Bot 103: 635-651. DOI: 10.3732/ajb.1500539

Taher D, Solberg SØ, Prohens J, Chou Y, Rakha M, Wu T. 2017. World vegetable center eggplant collection: Origin, composition, seed dissemination and utilization in breeding. Front Plant Sci 8: 1484. DOI: $10.3389 / \mathrm{fpls} .2017 .01484$

Tümbilen Y, Frary A, Mutlu S, Doganlar S. 2011. Genetic diversity in Turkish eggplant (Solanum melongena) varieties as determined by morphological and molecular analyses. Int Res J Biotechnol 2 (1): 1625 .

Wei Q, Du L, Wang W, Hu T, Hu H, Wang J, David K, Bao C. 2019. Comparative transcriptome analysis in eggplant reveals selection trends during eggplant domestication. Ind $\mathrm{J}$ Genomics. DOI: $10.1155 / 2019 / 7924383$ 